\title{
Introduction
}

Alan J. Abramson*

\section{Strengthening the U.S. Nonprofit Sector and Philanthropy: Policy Proposals from the 2019 ARNOVA-Independent Sector Symposium on Nonprofit Public Policy Research}

https://doi.org/10.1515/npf-2020-0058

Received November 17, 2020; accepted November 17, 2020

The U.S. nonprofit sector plays a critical role in American society. Nonprofits partner with government to deliver vital health, human, educational, and other services; they are a significant economic force that employs 10 percent of the private workforce; they serve as an important voice for many groups - the disabled, the discriminated against, the poor, the infirm - that might not otherwise be represented in the policymaking process; they are receptive to the selfexpression of artistic, religious, and other values; and they help bind diverse individuals together through volunteering, board membership, and other types of shared service and civic engagement.

Unfortunately, despite the significant contribution that the nonprofit sector makes to society, the sector remains a mystery to many policymakers who seem to know that the sector exists but who often overlook its capacities and needs when making important policy decisions. When Americans are unemployed, policymakers fail to look to the nonprofit sector as an important place to put people back to work. When people are sick or in need of help, policymakers don't understand the important role the nonprofit sector plays in providing assistance and restoring hope. When society frays, policymakers miss the potential of the nonprofit sector to bring us together through common service. And policymakers typically fail to recognize the ways government and public policy can help strengthen the nonprofit sector and improve its capacity for doing its important work.

\footnotetext{
*Corresponding author: Alan J. Abramson, Schar School of Policy and Government, George Mason University, Arlington, VA, 22201, USA, E-mail: aabramso@gmu.edu
} 
In 2010, to address the lack of policymaker understanding of the nonprofit sector and increase the attention of nonprofit scholars to policy-related issues, the Association for Research on Nonprofit Organizations and Voluntary Action (ARNOVA), the nation's leading association of nonprofit researchers, established an annual symposium focused on stimulating nonprofit policy research and commentary. In 2019, ARNOVA teamed up with the organization Independent Sector, the premier umbrella association in the U.S. representing both public charities and private foundations, to co-host the eighth annual nonprofit public policy symposium. This issue of Nonprofit Policy Forum contains revised versions of six of the policy papers presented at that symposium.

Planning for the 2019 policy symposium began with the development of a request for policy proposals addressing a broad range of topics:

- Tax policy that affects charitable giving by donors of all backgrounds and economic status;

- Issues related to the tax-exempt status of nonprofits;

- Oversight of the nonprofit sector and philanthropy;

- How government is structured to address nonprofit issues;

- Government laws and regulation related to nonprofit lobbying, electoral activity, or other issues;

- Government contracting arrangements with nonprofits;

- Foundation-related policy issues;

- Government data about and affecting the nonprofit sector, including the quality, accessibility, timeliness, and transparency/privacy of data from the Bureau of Labor Statistics, Bureau of Economic Analysis, Census Bureau, and other government agencies;

- Public policy that encourages civic participation, volunteerism, advocacy, and community service; and

- Government laws and regulations affecting nonprofit staff.

Following the review of submitted proposals by a team of nonprofit scholars and leaders, eight proposals were selected for presentation at the 2019 policy symposium. The symposium, which was held on July 29, 2019 at Independent Sector's office in Washington, DC, was attended by 35 nonprofit researchers and leaders. Many of the policy proposals that were discussed at the July symposium were presented again at ARNOVA's annual conference in November 2019 and then submitted to NPF for peer review and possible inclusion in this special issue. In the end, six policy proposals were selected to appear in this issue, including: two research articles, one by Nicolas Duquette and a second co-authored by Patrick Rooney, Sasha Zarins, Jonathan Bergdoll and Una Osili; two policy briefs, one by Jeffrey Berry and the other co-authored by Putnam Barber and Steven Rathgeb Smith; and two commentaries, one by Ronan Brooks and the other by Shirley Sagawa. 
Notably, many of the papers in this special issue were developed with input from both nonprofit scholars and nonprofit leaders. In one case, the paper by Putnam Barber and Steven Rathgeb Smith, the authors themselves are a former nonprofit executive and a scholar, respectively. In other cases, the issues being addressed were identified as important by nonprofit leaders and the research was carried out by academics. For example, the paper by Rooney et al. draws on research commissioned by the nonprofit leadership organization Independent Sector, and the paper by Nicolas Duquette stemmed in part from interest and support from the Council of Michigan Foundations. Jeffrey Berry's paper has its roots partly in important research on nonprofit advocacy that he completed some years ago with collaborators from OMB Watch and Charity Lobbying in the Public Interest. Ronan Brooks, who is now a law student at the University of Minnesota, drafted his paper while an intern at the Minnesota Council of Nonprofits. These kinds of collaborations between practitioners and researchers, where the former take the lead in identifying problems of concern, and the latter manage the research, are a fruitful way to conduct policy-relevant nonprofit research that is useful to the nonprofit community.

Accordingly, each of the policy proposals discussed in this issue addresses a problem of direct concern to nonprofit leaders. The research articles by Duquette and Rooney et al. are motivated in part by the declining percentage of all households who donate to charity. As Rooney et al. point out, the share of households who contribute to nonprofits declined from 67 percent of all households in 2000 to 56 percent of households in 2014, with the decrease especially marked among middle and low-income households. And, as both papers observe, the decline in contributing middle and low-income households was accelerated by the 2017 Tax Cut and Jobs Act (TCJA) which significantly raised the standard deduction, thereby eliminating the tax break for charitable giving for many of those who had previously itemized their deductions.

In response to the declining share of households who donate and the reduction in giving amounts that resulted from passage of the TCJA, both Duquette and Rooney et al. discuss a variety of tax changes that would restore incentives to give and boost giving by middle and low-income taxpayers. Duquette analyzes a two-tiered, charitable tax credit that would increase equity in the tax break for giving and encourage large gifts, all at a modest cost to the U.S. Treasury. Rooney et al. analyze five tax incentive proposals, including both itemized deductions and tax credits for charitable giving with various floors and ceilings. The researchers find that all five options would boost overall giving and the number of donor households at all income levels.

The problem that Berry and Brooks address in their papers is a perceived lack of lobbying and civic engagement activity by nonprofits and foundations. Current 
IRS regulations allow charitable nonprofits to engage in lobbying as long as lobbying does not comprise a substantial part of their activities. For Berry, the mistaken belief by many nonprofit leaders that their organizations are not permitted to lobby at all has weakened the voice of their organizations and, by extension, their clients in policymaking. To address this problem, Berry's policy brief proposes three administrative changes, including strong statements by the IRS that nonprofit lobbying is legal; clear definitions of what lobbying involves; and setting the h-election, which is explicit about how much lobbying nonprofits can do, as the default condition for nonprofits rather than something they have to proactively opt into.

Brooks's commentary focuses on IRS Section 4945(f)(2), which restricts foundations from supporting nonprofit voter registration drives unless the foundations support these drives in five or more states. Brooks suggests that this curb has roots in racist concerns about foundation support for civil rights initiatives, and calls for the repeal of this restriction which he suggests would result in more state and local nonprofits engaging in voter registration activity with foundation support.

For Barber and Smith, the problem is poorly targeted government oversight of the nonprofit sector, which puts too heavy a burden on small and medium-size, "classic," community-based nonprofits and pays too little attention to monitoring big, complex nonprofits more likely to engage in large-scale misdeeds. The proposed remedy is to simplify registration and reporting requirements for small nonprofits and thereby free up IRS resources to better oversee bigger, more complicated nonprofit organizations. Barber and Smith would also review data collected from nonprofits by the IRS, such as through IRS Form 990, to ensure that the information requested from nonprofits best meets the needs of regulators, donors, scholars, and the public at large.

Finally, Sagawa worries that the nonprofit sector, although it employs 10 percent of the private workforce, may face a shortage of interested workers in the years to come. Her commentary suggests that national service should be seen as a source of workforce development, or on-the-job training, for the nonprofit sector, where national service participants receive a kind of civic apprenticeship and learn the skills needed for future work in the sector.

The papers in this special issue reflect the fact that significant advances have been made in increasing the quality and quantity of nonprofit policy research and commentary. However, further progress is needed, including better nonprofit data and increased funding to support policy-relevant research. Some of the authors in this special issue use data about nonprofits that is currently available from 990 forms, the philanthropy module of the Panel Study of Income Dynamics (PSID), and tax models that incorporate tax provisions related to charitable giving. However, as Barber and Smith suggest, more relevant data is needed. A new 
Independent (2020) report, "The Health of the U.S. Nonprofit Sector," calls for improving the quality and timeliness of data on the sector's health and engaging nonprofit leaders in making sense of the data. The report specifically cites a need for increased numbers of nonprofit surveys that use random sampling. These more sophisticated studies would complement the many surveys that use convenience samples, which are helpful but which also have significant limitations. I would add that developing the capacity for regular surveying of nonprofits would be a nice supplement to the one-shot surveys that are currently the norm.

Improving policy-relevant data on nonprofits will undoubtedly require some additional funding, and nonprofit researchers and leaders must continue to advocate for increased support from foundations, government, and other sources for high-priority, policy research. At the same time, research can advance by drawing on governmental and other databases that already exist but which contain nonprofit data that is not regularly analyzed. In terms of federal government data, the Bureau of Labor Statistics, the Bureau of Economic Analysis, the Census Bureau, and other agencies already collect nonprofit data that are not fully utilized. The federal government should partner with nonprofit researchers and leaders to ensure that these data sources are accessible for studies and commentaries like the ones in this issue and others that are needed to shed light on the still too obscure nonprofit sector.

Acknowledgments: The author thanks Jeffrey Moore and Allison Grayson of Independent Sector and other staff at Independent Sector and ARNOVA for their great help in organizing the 2019 Nonprofit Policy Symposium.

\section{Reference}

Independent Sector. 2020. Health of the U.S. Nonprofit Sector. Washington, DC: Independent Sector. https://independentsector.org/nonprofithealth/\#: :text=Nonprofits\%20provide\% 20a\%20significant\%20portion,over\%20the\%20past\%20150\%20years (accessed November 14, 2020). 